University of Wollongong

Research Online

Faculty of Engineering and Information

Faculty of Engineering and Information

Sciences - Papers: Part B

Sciences

2020

\title{
Nitrite admixed concrete for wastewater structures: Mechanical properties, leaching behavior and biofilm development
}

\author{
Xuan Li \\ University of Queensland \\ Liza O'Moore \\ University of Queensland \\ Simeon Wilkie \\ University of Queensland, Getty Conservation Institute \\ Yarong Song \\ University of Queensland \\ Jing Wei \\ University of Queensland
}

See next page for additional authors

Follow this and additional works at: https://ro.uow.edu.au/eispapers1

Part of the Engineering Commons, and the Science and Technology Studies Commons

Research Online is the open access institutional repository for the University of Wollongong. For further information contact the UOW Library: research-pubs@uow.edu.au 


\title{
Nitrite admixed concrete for wastewater structures: Mechanical properties, leaching behavior and biofilm development
}

\author{
Abstract \\ This study systematically investigated the impacts of calcium nitrite addition on the mechanical \\ properties and biofilm communities of concrete-based wastewater infrastructures using sulfate resistant \\ cement through standard tests and DNA sequencing, respectively. The results revealed that setting time \\ and water demand for normal consistency were reduced, but slump, drying shrinkage, and apparent \\ volume of permeable voids increased with calcium nitrite dosage up to $4 \%$ weight of cement. The \\ cumulative leached fraction of nitrite, 28-day compressive strength and biofilm communities were not \\ significantly affected by calcium nitrite dosages. The addition of calcium nitrite into concrete is \\ environmentally friendly to wastewater infrastructures.

\section{Disciplines} \\ Engineering | Science and Technology Studies

\section{Publication Details} \\ Li, X., O'Moore, L., Wilkie, S., Song, Y., Wei, J., Bond, P. L., Yuan, Z., Hanzic, L. \& Jiang, G. (2020). Nitrite \\ admixed concrete for wastewater structures: Mechanical properties, leaching behavior and biofilm \\ development. Construction and Building Materials, 233 117341-1-117341-9.

\section{Authors} \\ Xuan Li, Liza O'Moore, Simeon Wilkie, Yarong Song, Jing Wei, Philip Bond, Zhiguo Yuan, Lucija Hanzic, and \\ Guangming Jiang
}


4 Xuan Li ${ }^{\text {a }}$, Liza O'Moore ${ }^{\text {b }}$, Simeon Wilkie ${ }^{\text {a, c }}$, Yarong Song a , Jing Wei a , Philip L. Bond ${ }^{\text {a }}$, 5 Zhiguo Yuan ${ }^{\text {a }}$, Lucija Hanzic ${ }^{\text {b }}$, Guangming Jiang a, d, *

$6{ }^{a}$ Advanced Water Management Centre, the University of Queensland, Australia

$7 \quad \mathrm{~b}$ School of Civil Engineering, the University of Queensland, Australia

$8{ }^{\mathrm{c}}$ Getty Conservation Institute, Los Angeles, USA

9 d School of Civil, Mining and Environmental Engineering, University of Wollongong, 10 Australia

12 XL: xuan.li@awmc.uq.edu.au; LO: 1 .omoore@uq.edu.au SW: $\underline{\text { swilkie@getty.edu }}$

13 YS: yarong.song@awmc.uq.edu.au PB: p.bond@uq.edu.au; ZY: z.yuan@,awmc.uq.edu.au

14 * Corresponding author. E-mail: gjiang@uow.edu.au; g.jiang@awmc.uq.edu.au; Tel.: +61 02 1542213792.

\section{Highlights:}

- A systematical study of the impact of calcium nitrite addition in sewer structures

- Mechanical property changes in concrete is proportional to calcium nitrite dosages

- Concrete with up to $4 \%$ calcium nitrite meets the structural requirement

- Nitrite leached to receiving water is proportional to the level of addition 
25 This study systematically investigated the impacts of calcium nitrite addition on the mechanical 26 properties and biofilm communities of concrete-based wastewater infrastructures using sulfate

27 resistant cement through standard tests and DNA sequencing, respectively. The results revealed 28 that setting time and water demand for normal consistency were reduced, but slump, drying 29 shrinkage, and apparent volume of permeable voids increased with calcium nitrite dosage up 30 to $4 \%$ weight of cement. The cumulative leached fraction of nitrite, 28-day compressive 31 strength and biofilm communities were not significantly affected by calcium nitrite dosages.

32 The addition of calcium nitrite into concrete is environmentally friendly to wastewater 33 infrastructures.

34

35

36 Keywords: Calcium nitrite, Concrete, Corrosion, Sewer, Biofilm, Sulfate resistant cement 
38 Civil infrastructure systems, such as sewer networks, are critical and essential parts of modern societies. With socio-economic development and population growth, the demand for such infrastructure has increased greatly. To ensure the durability and reliability of the sewer 41 infrastructure, steel-reinforced concrete is widely applied due to its high compressive and 42 tensile strength [1]. However, significant deterioration caused by sulfate attack, chloride penetration and biodeterioration commonly occurs in the structures subject to aggressive environments and can ultimately lead to early structural failure [2, 3].

Wastewater infrastructures, including sewer networks and wastewater treatment plants, are often exposed to aggressive environments. Sourced from sewage, sulfate attacks concrete 47 infrastructures that are fully or partially submerged in sewage [4]. In submerged parts of 48 infrastructures, sulfate from sewage attacks the cementitious paste of the concrete through direct contact forming ettringite and gypsum. These reactions are high expansive and cause the cracking and disintegration of the concrete [5]. In partially submerged structures, such as in gravity sewers, sulfate in sewage can be transformed into hydrogen sulfide and released into sewer gas. In the sewer the high moisture, microbial inoculation and supply of nutrients coming from wastewater, provide favorable conditions for the biological sulfide oxidation and acid production [6]. Subsequently, $\mathrm{H}_{2} \mathrm{~S}$ in sewer gas is oxidized into sulfuric acid on the concrete surface and attacks the concrete above the water level [7]. Both the sulfate attack from wastewater and sulfuric acid form on the concrete surface produces expansive corrosion

57 products, and weakens the structural capacity [8]. Iron in the concrete facilitates the 58 development of cracks along the corrosion front, and enhances the erosion of the concrete protection layer [9]. Due to the expansive corrosion products and cracks, water and oxygen availabilities to the steel increase significantly, which further accelerates the corrosion of the rebar steel $[10,11]$. In most of the countries, sulfate resistant cement is required to be used for 
sewer manufacture due to the exposure environment [12] [13]. Fly ash, a type of pozzolan, is a common admixture in sulfate resistant cement [14]. The addition of fly ash in cement reduces the calcium hydroxide content and permeability of concrete, which increases the resistance of concrete to the attack from sulfate [15].

In addition to sulfate attack, chloride ingress is another major cause of the rebar steel corrosion [16]. Penetrating through cracks or pore structures in concrete, chloride reaches the steel and depassivates the protective layer of steel. After the depassivation, steel corrosion initiates and produces expansive corrosion products, i.e. iron rust. Similar to the sulfate attack, the expansive corrosion products induce the cracking process and accelerate the steel corrosion [4]. Chloride is ubiquitous in sewage and it can be at very high levels when the residual chloride from the application of de-icing agents enters into sewers in winters [2]. Furthermore, some coastal cities (e.g. Hong Kong) have very high chloride in the wastewater system due to the use of seawater for toilet flushing [17]. Therefore, the ingress of sulfate and chloride causes a combination of rebar corrosion and concrete cracking, resulting in the accelerated deterioration of concrete-based wastewater infrastructures [2].

Calcium nitrite has been widely used as a corrosion inhibitor against chloride attack of rebar steel for several decades [18]. Calcium nitrite increases the chloride threshold level and also the corrosion-free life of concrete [19]. However, the addition of calcium nitrite is reported to change the physical and mechanical properties of concrete. Calcium nitrite accelerates the formation of calcium hydroxide and increases the total volume of pore structures in concrete, which weakens the resistance of concrete to sulfate attack [20]. The addition of calcium nitrite in ordinary Portland cement (OPC) usually increases the air content, the workability of fresh concrete and the cumulative pore volume of hardened concrete. Nitrite is reported to affect the compressive strength of the concrete positively or negatively depending on different mix designs [21-23]. However, there is no report on the impacts of admixing calcium nitrite with 
87 sulfate resistant cement on the properties of concrete. To investigate the feasibility of adding calcium nitrite as an admixture into sulfate resistant cement for wastewater structures, it is essential to understand the changes in fresh and mechanical properties under different calcium nitrite levels.

91 Inevitably, sewage structures are fully or partially submerged in wastewater. Leaching of nitrite 92 into wastewater is thus a major concern for sewage structures using nitrite-admixed concrete. 93 A sufficient level of nitrite in concrete is a key factor for achieving the inhibitory effect on steel corrosion [24]. A previous study using OPC found that the leaching behavior of nitrite is affected by the curing time, mix design and temperature [25]. The leaching behavior of nitrite admixed with sulfate resistant cement at different dosages has not been investigated.

97 Furthermore, biofilms develop on the concrete surface in the sewer system and downstream wastewater treatment facilities [26]. Nitrite-admixed concrete may affect the wastewater biofilms due to the inhibitory effects of nitrite on microorganisms. Depending on the $\mathrm{pH}$ and nitrite concentration, inhibitory and biocidal effects are observed on sulfate-reducing bacteria (SRB) and methanogens in anaerobic sewer biofilms, and on ammonia-oxidizing bacteria and polyphosphate-accumulating organisms in the wastewater treatment process [27]. These effects may be desired or undesired for the benefit of wastewater management. Regardless, it is necessary to understand the potential impact of nitrite admixed with sulfate resistant cement on the activity and development of biofilms in wastewater.

Collectively speaking, this study aims to investigate the impact of calcium nitrite and its

107 dosages as an admixture with sulfate resistant cement on the fresh and hardened concrete 108 properties, the nitrite leaching behavior and the biofilms on the concrete surface. Five different 109 dosages of calcium nitrite were employed to cast test specimens. The relationship between the concrete properties and nitrite dosages was determined and analyzed with regression models.

111 Nitrite leaching performance was tested for three different calcium nitrite dosages over 15 
112 months. Laboratory-scale anaerobic wastewater reactors were used to monitor the development

113 of biofilms on the nitrite-admixed concrete with three different dosages in real domestic

114 sewage over six months. This systematical investigation will support the development and

115 application of nitrite-admixed concrete for durable, resilient and sustainable wastewater

116 infrastructures.

117 2. Materials and methods

$118 \quad 2.1$ Ingredients and mix design

119 General Blended sulfate-resistant cement (Cement Australia Builders Cement), in compliance

120 with AS 3972 [28] was adopted as the primary binder in this study. This cement contains 75121 $95 \%$ of Portland cement clinker, $5-25 \%$ fly ash and $0-5 \%$ minor additional constituents.

122 The coarse aggregates were crushed aggregate (CA) with a nominal maximum particle size of

$12310 \mathrm{~mm}$, specific gravity (SG) of 2.89, fineness modulus of 4.17, and water absorption (A) of $1240.28 \%$. Three fine aggregates including crushed manufactured sand (MS), natural river sand 125 (RS) and natural fine sand (FS) have a specific gravity of 2.91, 2.67 and 2.66, fineness modulus 126 of $4.82,7.26$ and 8.94 , water absorption of $0.56 \%, 2.41 \%$ and $1.61 \%$, respectively.

127 A conventional concrete mix design (industrial based), typically used in sewer pipes for sulfate 128 exposure class, was adopted in this study (Table 1). A water/cement (w/c) ratio of 0.4 was used 129 in all the mixes. The key parameter examined experimentally was the dosage of calcium nitrite 130 by weight $\left(0 \%, 1 \%, 2 \%, 3 \%, 4 \%\right.$ of cement weight). Calcium nitrite $\left(\mathrm{Ca}\left(\mathrm{NO}_{2}\right)_{2}\right)$ solution $(30$ 131 wt. \% in $\mathrm{H}_{2} \mathrm{O}$, Sigma-Aldrich) was applied according to the mix design (Table 1). 132 Polycarboxylate ether polymers superplasticiser (MasterGlenium SKY 8700, BASF) was 133 added to achieve the desired workability (Table 1). 
Table 1 Summary of mix designs used for concrete properties study

\begin{tabular}{|c|c|c|c|c|c|c|c|c|c|c|}
\hline \multirow{3}{*}{$\begin{array}{c}\text { Calcium } \\
\text { nitrite dosage }\end{array}$} & \multicolumn{10}{|c|}{ Constituents $\left(\mathrm{kg} / \mathrm{m}^{3}\right)$} \\
\hline & \multirow{2}{*}{$\mathbf{w} / \mathbf{c}$} & \multirow{2}{*}{ Cement } & \multirow{2}{*}{$\begin{array}{l}\text { Free } \\
\text { water }\end{array}$} & \multirow{2}{*}{$\mathrm{Ca}\left(\mathrm{NO}_{2}\right)_{2}$} & \multicolumn{5}{|c|}{ Aggregates $^{\text {a }}$} & \multirow{2}{*}{ S.P. ${ }^{\mathbf{b}}(l)$} \\
\hline & & & & & $10 \mathrm{~mm}$ & MS & RS & FS & TOTAL & \\
\hline $0 \%$ & 0.4 & 420 & 168 & 0 & 750 & 375 & 469 & 281 & 1876 & 4.2 \\
\hline $1 \%$ & 0.4 & 420 & 168 & 4.2 & 749 & 374 & 468 & 281 & 1871 & 4.2 \\
\hline $2 \%$ & 0.4 & 420 & 168 & 8.4 & 747 & 373 & 467 & 280 & 1867 & 4.2 \\
\hline $3 \%$ & 0.4 & 420 & 168 & 12.6 & 745 & 372 & 466 & 279 & 1862 & 4.2 \\
\hline $4 \%$ & 0.4 & 420 & 168 & 16.8 & 743 & 372 & 464 & 279 & 1858 & 4.2 \\
\hline
\end{tabular}

136

$\overline{{ }^{a} \text { In aggregates, } 10 \mathrm{~mm}, \mathrm{MS}, \mathrm{RS}, \mathrm{FS} \text { are the coarse aggregates, manufactured sand, natural river sand and }}$ natural fine sand, respectively.

${ }^{\mathrm{b}}$ S.P.: superplasticizer.

\subsection{Mixing, casting and curing procedure}

Concrete mixing was carried out in accordance with AS 1012.2 [29], in a conforming revolving pan mixer (Bennet 70L laboratory mixer). The mixing procedure was as follows: firstly, the coarse aggregate followed by the fine aggregate were hand loaded into the concrete mixer with a sufficient quantity of mixing water (approximately 50\%) and mixed for 30 seconds. Then cement was added and covered with some of the aggregates. After that, the ingredients were mixed for 2 minutes and the remaining mix water and admixture (calcium nitrite and superplasticisers) were added within the first minute of mixing. After mixing, the mixer was stopped to rest for 2 minutes and operated for a further 2 minutes. The slump was measured within 3 minutes of stopping the mixer (section 2.3.2). After slump measurement, another 2 minutes of mixing was applied and then the fresh mixtures were filled into the molds for compressive strength measurements (section 2.3.3), drying shrinkage measurements (section 2.3.4) and apparent volume of permeable voids measurements (section 2.3.5). The mixture was consolidated on a vibration table within the next 20 minutes. Immediately after compaction, 
any molds with an exposed surface were placed under wet hessian sheets to provide a moist environment for curing. All samples were stored in the concrete laboratory for $23 \pm 2$ hours. After this time, they were demolded and transferred to curing tanks. To avoid crosscontamination, samples from different mixes were cured separately in lime-saturated water, at a standard tropical zone temperature of $27 \pm 2{ }^{\circ} \mathrm{C}$ until the appropriate testing age.

2.3 Sample preparation and testing procedure

\subsubsection{Fresh properties}

The water demands for normal consistency and setting time for the cement with five different dosages of calcium nitrite $(0 \%, 1 \%, 2 \%, 3 \%$ and $4 \%)$ were tested on cement pastes in accordance with AS/NZS 2350.4 [30]. Slump tests and plastic density tests were conducted on fresh concrete immediately after mixing according to AS 1012.3.1 [31].

\subsubsection{Compressive strength}

Compressive strength tests were carried out on the concrete in accordance with AS 1012.9 [32], using cylindrical molds of dimensions $\emptyset 100$ x $200 \mathrm{~mm}$. Three cylinders from each mix were cast as mentioned in section 2.2 and used for the compressive strength measurements at an age of 28 days. A force was applied continuously at a rate of $20 \pm 2 \mathrm{MPa}$ compressive stress per minute until no increase in force could be sustained, and the maximum force applied was recorded.

\subsubsection{Drying shrinkages}

Triplicate specimens for each concrete mix were cast in prism molds of dimensions $280 \times 75$ x $75 \mathrm{~mm}$ conforming to AS 1012.8.4 and cured as described in section 2.2 [33]. At an age of seven days from molding, samples were removed from the curing tanks, wiped with a damp cloth, and placed in a drying chamber maintained at $23 \pm 1^{\circ} \mathrm{C}$ and $50 \pm 5 \%$ relative humidity in accordance to AS 1012.13 [34]. The first reading was completed within 2 minutes of removing 
the specimen from the curing tanks. Subsequent readings were taken for each specimen, after drying periods of $7,14,21,28$ and 56 days.

\subsubsection{The apparent volume of permeable voids}

Determination of the apparent volume of permeable voids (AVPV) in hardened concrete was carried out in accordance with AS 1012.21 [35]. Test specimens were prepared by casting using $\varnothing 100 \times 200 \mathrm{~mm}$ test cylinders, cured as mentioned in section 2.2. Then, after up to $3 \mathrm{~mm}$ of the top surface of each cylinder was trimmed off, each cylinder was cut into four equal slices. The slices were dried in an oven at a temperature of $105 \pm 5^{\circ} \mathrm{C}$ for $24 \mathrm{~h}$, cooled in desiccators to a temperature of $23 \pm 2^{\circ} \mathrm{C}$ and weighed individually $\left(M_{l}\right)$. Then, the specimen slices from different mixes were immersed separately in distilled water at $23 \pm 2{ }^{\circ} \mathrm{C}$ for not less than $48 \mathrm{~h}$ and then boiled for a period of $5.5 \pm 0.5 \mathrm{~h}$. The slices were then kept in the water until cooled to a final temperature of $23 \pm 2{ }^{\circ} \mathrm{C}$ and weighted individually $\left(M_{2}\right)$. Each slice was then suspended on a rack and immersed in water at $23 \pm 2{ }^{\circ} \mathrm{C}$ and the mass was recorded as $M_{3}$. All the weight measurements were performed at an accuracy of $0.01 \mathrm{~g}$. The apparent volume of permeable voids (AVPV) was calculated as:

$$
A V P V=\frac{\left(M_{2}-M_{1}\right)}{M_{2}-M_{3}} \times 100 \%
$$

\subsection{Leaching of nitrite from admixed concrete}

The test methodology generally followed the specifications of ANSI/ANS- 16.1-1986 [36]. Triplicate specimens from each calcium nitrite dosage $(1 \%, 2 \%, 3 \%)$ were cast using cylindrical molds of dimensions $\varnothing 40 \times 40 \mathrm{~mm}$ and cured individually in one-liter limesaturated water at standard tropical zone temperature of $27 \pm 2{ }^{\circ} \mathrm{C}$ for 28 days. After curing, each cylinder was placed, supported by a plastic stand, inside a lidded plastic container with $800 \mathrm{~mL}$ deionized water (DI) at $24 \pm 0.5^{\circ} \mathrm{C}$. The DI water maintains a uniform thickness around the specimen providing a ratio of liquid solution volume to specimen surface area at $12.7 \mathrm{~cm}$. 
202 The leached solution was sampled and completely replaced by fresh DI water at regular intervals during cumulative leaching times ranging from 2 to $10320 \mathrm{~h}$ (over 430 days). For analysis of the leached nitrite concentration, $5 \mathrm{~mL}$ of leached solution was filtered $(0.22 \mathrm{~mm}$ membrane) and analyzed using a Lachat QuikChem 8000 (Milwaukee) flow-injection analyzer (FIA). To assess the leaching process, a cumulative fraction leached (CFL) was defined as the sum of the fractions of nitrite leached during all sampling intervals prior to and including the present interval divided by the amount of nitrite in the test specimen before the test. For the ith liquid replenishment, the CFL was calculated as

$$
C F L=\sum_{i=1}^{n} \frac{a_{i}}{A_{0}}
$$

211 where $A_{0}$ is the total amount of nitrite inside the specimen at the beginning of the leaching 212 experiment, which was calculated as the nominal admixed amount. And $a_{i}$ is the leached amount of nitrite at the i-th liquid replenishment interval.

215 Triplicate cylinders were cast with a diameter $\varnothing 2 \mathrm{~cm} \mathrm{x} 3 \mathrm{~cm}$ using the mortar from each of $2160 \%, 2 \%$ and $4 \%$ calcium nitrite mixes with coarse aggregates removed by a $4.75 \mathrm{~mm}$ sieve. 217 After casting, the specimens were cured as mentioned in section 2.2 for 28 days. Then, cylinders from each mix level were clustered on stainless-steel rods using cable ties and transferred to a lab-scale rising main sewer reactor (Figure S1) to simulate the anaerobic conditions in real sewers. Three reactors, made of Perspex with a volume of $0.75 \mathrm{~L}$, were built to provide a similar ratio of liquid solution volume to specimen surfaces area as leaching tests in section 2.4 .

Domestic wastewater collected weekly from a nearby wet well in Brisbane, Australia, was stored in a cold room at $4{ }^{\circ} \mathrm{C}$, and used as the feed to the reactors. The sewage typically contained sulfide at concentrations of $<3 \mathrm{mg}-\mathrm{S} / \mathrm{L}$, sulfate at $10-25 \mathrm{mg}-\mathrm{S} / \mathrm{L}$, total chemical 
oxygen demand (COD) and soluble COD at 450-600 mg/L and 260-450 mg/L, respectively, with the latter including volatile fatty acids (VFAs) at 50-120 mg-COD/L. The hydraulic retention time (HRT) of the reactors was maintained as 6 hours, a common HRT in sewers. The wastewater was preheated to room temperature before being pumped into the reactors through a peristaltic pump (Masterflex 7520-47). Each pumping event lasted 4 min for every 6 hours at the flow rate of $275 \mathrm{~mL} / \mathrm{min}$. Constant mixing was provided at $250 \mathrm{rpm}$ with a magnetic stirrer (Heidolph MR3000) to produce a moderate shear force at the inner surface of the reactor wall.

After 3 and 6 months of incubation, one cylinder from each type of concrete was removed from the reactor. The biofilm attached on the surface of each cylinder was collected using a sterile surgical scalpel into a sterile $50 \mathrm{~mL}$ polypropylene falcon tube and stored at $4{ }^{\circ} \mathrm{C}$ for less than $24 \mathrm{~h}$ before DNA was extracted.

The DNA was extracted from the biofilm samples using the Fast DNA ${ }^{\mathrm{TM}}$ SPIN Kit for Soil (MP Biomedicals, CA, USA), as per manufacturer's instructions. The extracted DNA samples were provided to the Australia Center for Ecogenomics (ACE, Brisbane, Australia) for 16S rRNA gene amplicon sequencing (Illumina). The extracted 16S rRNA gene was amplified using the universal primer set 926F (5'-AAACTYAAAKGAATTGACGG-3') and 1392R (5'ACGGGCGGTGTGTRC-3'). The resulting PCR amplicons were purified using Agencourt AMPure XP beads (Beckman Coulter). Then the purified DNA was indexed using the Illumina Nextera XT 384 sample Index Kit A-D (Illumina FC-131-1002) in standard PCR conditions with Q5 Hot Start High-Fidelity2X Master Mix. After that, Amplicons were pooled in equimolar concentration and sequenced with an Illumina sequencer (MiSeq Sequencing System) based on the standard protocols.

Raw sequencing data were quality-filtered and demultiplexed using Trimmomatic, with poor- 
251 similarity were clustered into operational taxonomic units (OTUs) using QIIME with default 252 parameters, and representative OTU sequences were taxonomically BLASTed against

253 Greengenes 16S rRNA database. Finally, an OTU table consisting of the taxonomic 254 classification and OTU representative sequences was used to analyze the microbial community 255 structure.

Linear regression analysis was performed on the properties of the paste or concrete including setting time, w/c for normal consistency, slump, density, compressive strength, drying shrinkage and apparent volume of permeable voids (AVPV) against calcium nitrite dosages using R (ver 3.31, http://www.R-project.org/). The linear regression typically generates the correlation in terms of a straight line which best approximates all the individual data points including target and output parameters [37]. The general form of the linear regression is given as equation 3:

$$
\hat{\mathrm{Y}}=a_{0}+\mathrm{b}_{0} \mathrm{n}
$$

265 Where $\hat{\mathrm{Y}}$ is the model's output, $\mathrm{n}$ is the calcium nitrite dosage $(\%)$, and $a_{0}, b_{0}$ are the regression 266 coefficients.

267 For each property, the significance of the non-zero slope was analyzed using F-test by the $p$ value. Then the linear regression models were built based on the data points obtained under 5 different dosages (i.e. $0,1,2,3,4)$ for the properties with significant non-zero slopes. The 270 coefficients of determination $\left(\mathrm{R}^{2}\right)$ were employed as the indicator to assess the performance of 271 linear regression models. 
274 Since setting time is related to the handling time of fresh concrete, a proper dosage is critical

275 for the use of calcium nitrite in industrial and commercial applications. In sulfate-resistant

276 cement pastes, the initial setting time and final setting time decreased due to the addition of

277 calcium nitrite (Figure 1A). With higher calcium nitrite dosages, higher reductions of initial

278 setting times and final setting times were observed (Figure 1A). In comparison to the control

279 without calcium nitrite, $42 \%$ and $36 \%$ reduction in the mix with $1 \%$ calcium nitrite and $58 \%$

280 and $42 \%$ reduction in the mix with $2 \%$ calcium nitrite were observed for the initial and final

281 setting time, respectively. In previous studies using OPC, the addition of calcium nitrite at 1\%

282 by weight, led to $31 \%$ and $16 \%$ reduction and $2 \%$ addition led to $65 \%$ and $44 \%$ reduction, in

283 initial setting time and final setting time, respectively [21]. In comparison to those previous

284 reports, the different reduction ratios in this current study might be caused by the different cement types. However, a higher accelerating effect due to a higher calcium nitrite dosage were observed in this current study and previous studies. In this study, for the mix with $4 \%$ calcium nitrite, the initial setting time and final setting time dropped to c.a. 18 minutes and c.a. 41 minutes, respectively. Based on the current mix design in this study, the higher nitrite dosage

$289(>4 \%)$ would lead to a very short and impractical setting time.

290 Through the linear regression analysis, no-zero slopes were confirmed for both initial setting ( $p=0.0067)$ and final setting time $(p=0.0060)$, respectively. Linear regression models were established for both initial setting time ( $t_{i}$, minutes) and final setting time ( $t_{f}$, minutes), with the 293 admixed level of calcium nitrite ( $n, \%$ ) (Figure 1A). The good fitting performance of these 294 models $\left(\mathrm{R}^{2}=0.94\right.$ in both cases $)$ suggests the potential of using the linear regression models for optimizing the calcium nitrite dosage and operational procedure for specified setting time. 

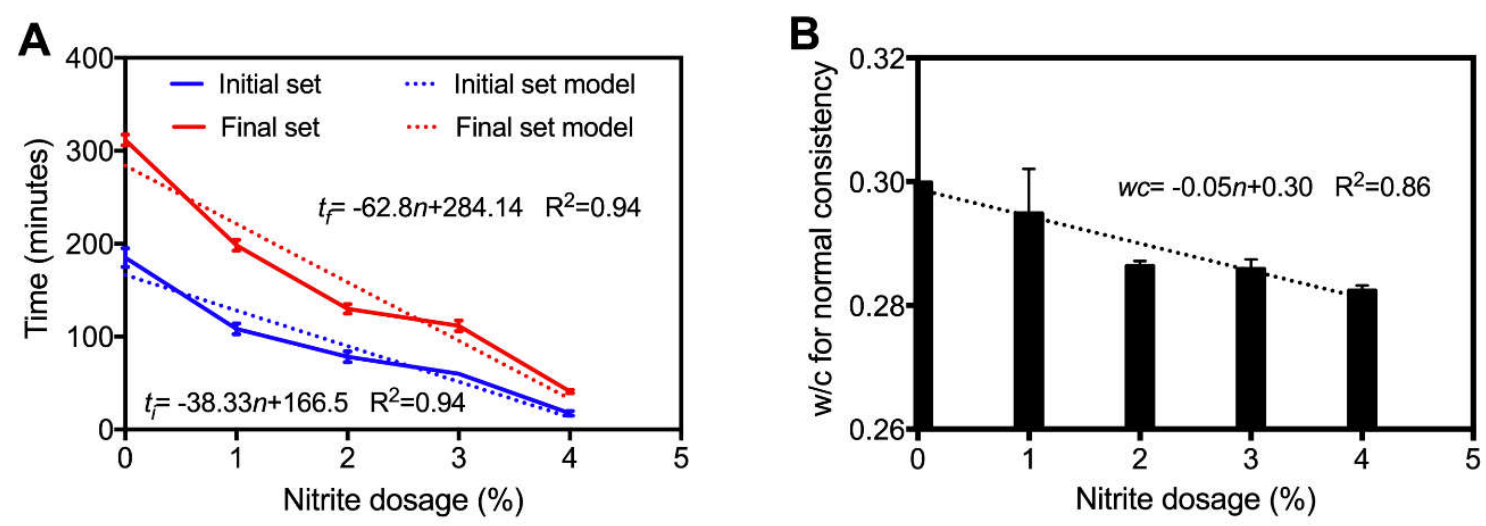

296

297 Figure 1 Setting time of cement pastes with various nitrite dosages (A); water/cement ratio for normal 298 consistency of cement pastes under 5 dosages of calcium nitrite (B).

299

The w/c needed for normal consistency of control mix ( $0 \%$ calcium nitrite dosage) is similar 300 to that in OPC [38]. The addition of calcium nitrite significantly reduced the water demand of the mix. For the $4 \%$ calcium nitrite admixed mix, the w/c needed for normal consistency was reduced from c.a. 0.30 to c.a. 0.28 , compared with the control mix. This suggests that less water is required for a desired consistency with the addition of calcium nitrite. The water demand is one of the most important criteria for mix design, which affects the fresh and hardened properties of concrete [39]. Through linear regression analysis, a non-zero slope was confirmed $(p=0.024)$. The linear regression model $\left(\mathrm{R}^{2}=0.86\right)$ can be employed to adequately determine the w/c for different admixture levels of calcium nitrite (Figure 1B).

\subsection{Slump and density}

The slump of fresh concrete significantly increased with the calcium nitrite addition (Figure $\mathrm{mm}$ to c.a. $253 \mathrm{~mm}$. Previously, slump increases from $75 \mathrm{~mm}$ to $95 \mathrm{~mm}$ and $55 \mathrm{~mm}$ to $90 \mathrm{~mm}$, 312 in OPC and blast furnace slag cement, with the addition of around $1.8 \%$ calcium nitrite by mass 313 of cement, are reported respectively [23]. Another study found that the slump increased from $31466 \mathrm{~mm}$ to $91 \mathrm{~mm}$ in OPC with the addition of $2 \%$ of calcium nitrite by the mass of cement [21].

315 The observation in this study is consistent with previous reports. Furthermore, the relationship 
316 between different calcium nitrite dosages and the slump has been clearly identified in this

317 study.

318 A significant non-zero linear slope was confirmed between the level of calcium nitrite ( $n, \%)$ 319 and the average slump (Slump) through linear regression analysis $(p=0.049)$, and the linear 320 regression model described the relationship well $\left(\mathrm{R}^{2}=0.78\right)$ (Figure 2$)$. This coincides with

321 the linear decreasing trend in the water demand of cement paste to achieve a normal consistency 322 under different calcium nitrite dosages (section 3.1). Since there are different methods for 323 constructing concrete pipes and each method requires different workability, there is no specific

324 limitation for the slump in the Australian standard for sewage-related infrastructures [13]. The 325 slump values measured in this study for all five mixes are within the range of normal weighted 326 aggregate concrete [40]. Consistent with the reduced water demand, to achieve a fixed slump, 327 less water will be required for the concrete with calcium nitrite as an admixture.

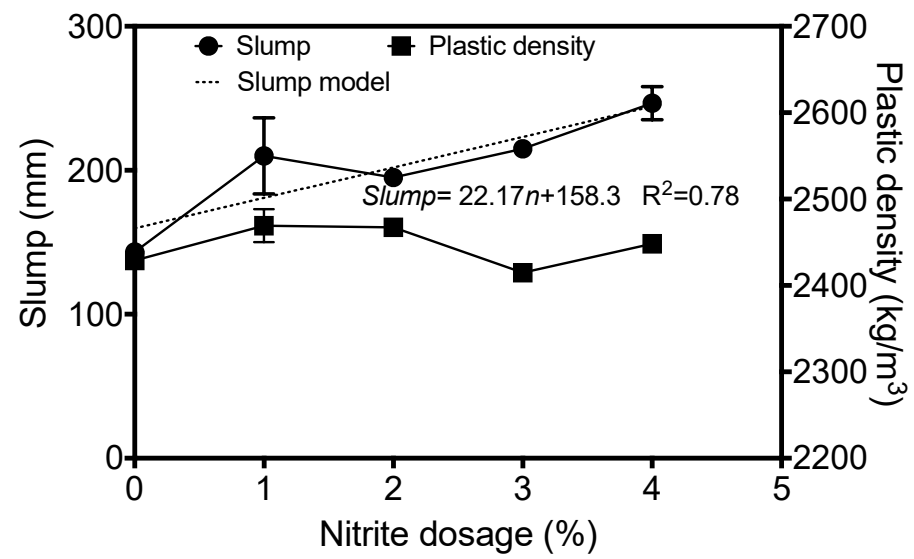

330 Through linear regression analysis, a non-zero slope between plastic density and nitrite dosage

331 was not significant $(p=0.86)$. Limited variations in plastic density were observed between 332 mixes of different calcium nitrite levels (Figure 2), suggesting that the plastic density was not 333 significantly affected by calcium nitrite addition and its dosage. The plastic density of the $3 \%$ calcium nitrite mix was slightly lower than other mixes, and this is likely caused by the higher 
335 air content in the 3\% fresh mix. The higher air content in the $3 \%$ mix, in turn, was most likely

336 due to incomplete consolidation resulting from accelerated setting. The plastic density of all

337 five mixes was between $2400 \mathrm{~kg} / \mathrm{m}^{3}$ to $2500 \mathrm{~kg} / \mathrm{m}^{3}$, which is equivalent to that of conventional 338 concrete [41].

$339 \quad 3.3$ Compressive strength and hardened density

340 For most sewer concrete, $50 \mathrm{MPa}$ is the minimum 28-day cylinder compressive strength

341 requirement and this was achieved for all the sulfate-resistant concrete with added calcium

342 nitrite at $0 \%, 1 \%, 2 \%, 3 \%$ and $4 \%$ (Figure 3 ). Due to calcium nitrite admixing, the compressive

343 strength increased in most of the previous studies [21, 23]. However, in some recent studies,

344 calcium nitrite showed an adverse impact on the compressive strength at the later stage of

345 curing, which might be attributed to the increase of micropore size during the hydration process

346 [22]. Through the linear regression analysis, the slope between 28-day compressive strength

347 and calcium nitrite dosage was not significantly non-zero $(p=0.96)$, suggesting the insignificant

348 impact of calcium nitrite addition on the 28-day compressive strength of concrete. The

349 observation is consistent with some previous studies [42, 43]. Since the concrete type, curing

350 condition, calcium nitrite dosage and types of other admixtures are different in each study, the

351 observation about the insignificant change of compressive strength might be limited to the current mix design and curing condition. 


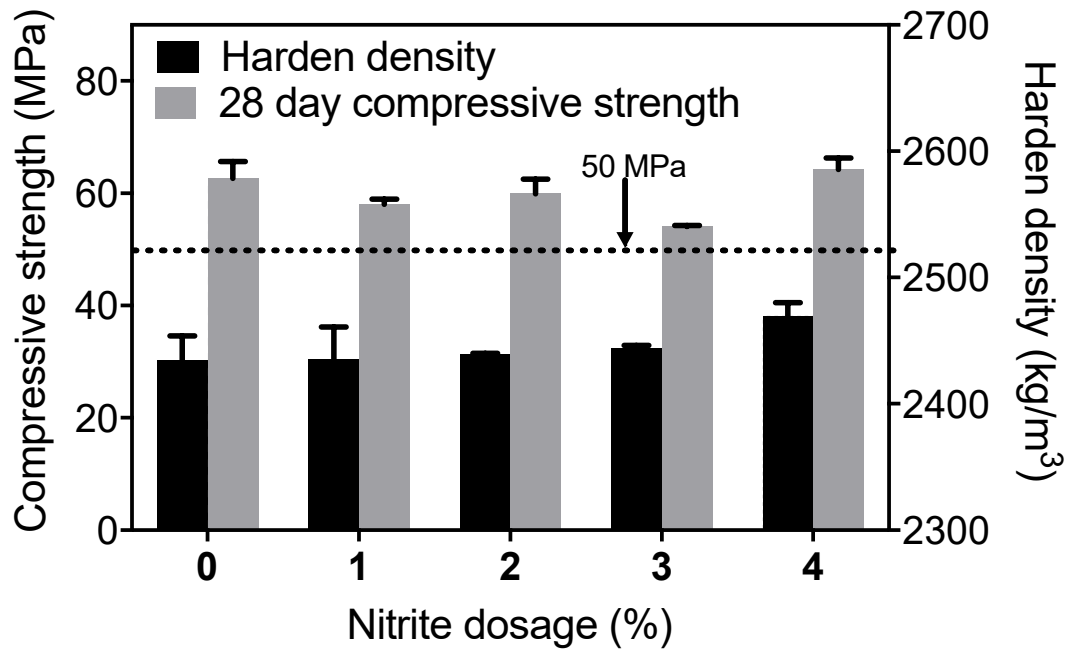

353

354

355

356

357

358

359

360

361

362

363

364

365

366

367

368

369

370

Figure 3 Compressive strength and hardened density of concrete under five calcium nitrite dosages

The hardened density of all the mixes was in the range of $2400-2500 \mathrm{~kg} / \mathrm{m}^{3}$, which is similar to most of the concrete manufactured with OPC [23]. Although there is a slight increase of hardened density with a higher nitrite dosage, the non-zero slope between hardened density and calcium nitrite dosage was insignificant $(p=0.07)$ (similar to the plastic density) and variations observed between mixes of different calcium nitrite levels are limited (Figure 3).

\subsection{Drying shrinkage and permeable voids}

The addition of calcium nitrite increased the drying shrinkage and higher shrinkage was observed with higher doses of calcium nitrite (Figure 4A). Through the linear regression analysis, the non-zero slope between drying shrinkage and calcium nitrite dosage gradually became significant with $p$ values decreasing from 0.063 at day 7 to 0.045 at day 28 , and 0.030 at day 56 (Table S1). In hardened concrete, drying shrinkage is the volume of water lost from hardened concrete stored in unsaturated air [44]. The increased drying shrinkage especially at later stages (after 21 days), suggested a higher volume of water loss from concrete due to a higher calcium nitrite dosage. The water lost during drying shrinkage is the excess from the mix which does not react with the cement, but is required to aid compaction and workability, and becomes trapped in the pores of the hardened cement paste [45]. As discussed in section 
3713.1 , the calcium nitrite addition reduced the water demand for cement paste, which in turn

372 increased the volume of water that was lost from hardened concrete samples at constant $\mathrm{w} / \mathrm{c}$ in

373 drying shrinkage tests. In addition, due to the acceleration effect caused by calcium nitrite, a

374 more porous microstructure of cement paste is likely to be formed during the hydration process,

375 which would increase the volume of water loss during the drying shrinkage testes[22].

376

377

378

379 The drying shrinkage observed at day 56 for all five mixes were within a range of $0.061 \%$ to

Figure 4 Drying shrinkage (A) and apparent volume of permeable voids (AVPV) (B) of concrete with different calcium nitrite dosages
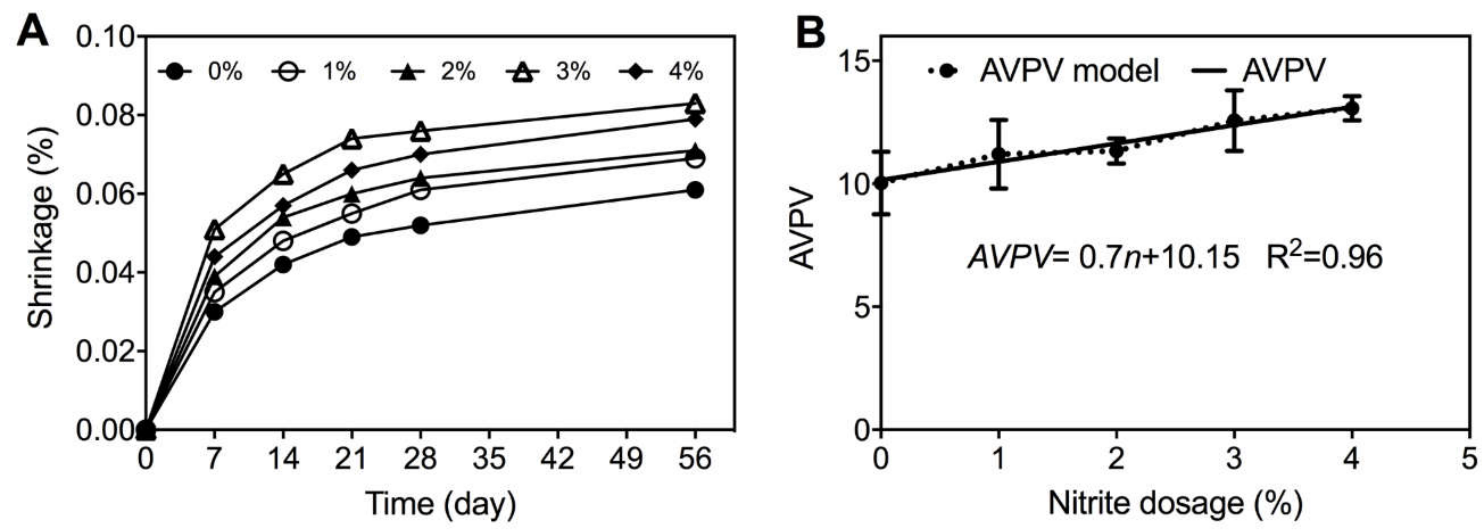

$380 \quad 0.083 \%$. Such results are in line with previous studies where calcium nitrite has been used as

381 an admixture [46, 47]. There is no specific requirement for wastewater infrastructures in

382 Australia regarding drying shrinkage. However, according to the standard regarding concrete

383 structures for retaining liquids, the drying shrinkage measured in 56 days should be less than

$3840.07 \%[13]$. The drying shrinkage of mixes with $3 \%$ and $4 \%$ of calcium nitrite were just above

385 this limit. Due to the evaporation of free water in capillary pores, drying shrinkage occurs and

386 this induces the transport of water particles from calcium silicate hydrates $(\mathrm{C}-\mathrm{S}-\mathrm{H})$ to the

387 capillary pores. This circumstance produces internal stress, mass loss and consequently volume

388 reduction of the concrete and becomes one of the main causes for the cracking of restrained concrete [48]. In this study, the higher drying shrinkage due to calcium nitrite addition may 
increase the potential of cracking. Therefore, for better durability, the dosage of calcium nitrite should be optimized to prevent the adverse effects of shrinkage.

392 For the apparent volume of permeable voids (AVPV), the addition of calcium nitrite increased AVPV in a linear pattern. Through linear regression analysis, the non-zero slope between

394 AVPV and calcium nitrite dosages ( $\mathrm{n}, \%)$ was significant $(p=0.0036)$, and the linear regression 395 model described the data well $\left(\mathrm{R}^{2}=0.96\right)$ (Figure 4B). The AVPV in hardened concrete is affected by the extra water added in the mix since it increases the capillary porosity of concrete [49]. The linear increase of AVPV with increased calcium nitrite additions is consistent with the reduced water demand for cement paste (section 3.1) and increased drying shrinkage detected at the higher doses.

The AVPV increased from $10.0 \%$ in the control mix ( $0 \%$ calcium nitrite) to $13.1 \%$ in the $4 \%$ calcium nitrite mix. The AVPV observed for control mix is similar to most of the OPC concrete and fly ash blended concrete $[50,51]$. For wastewater infrastructures, the increased AVPV would provide increased access of chloride and sulfate ingress, which may accelerate both steel and concrete corrosion. In addition, although there is no specific requirement for sewagerelated infrastructures regarding AVPV, a concrete with AVPV values less than $13 \%$ is generally classified as good-quality concrete for bridges and roads [52]. For the mixes with calcium nitrite dosages lower than 4\%, the AVPV were all below this limit, suggesting limited pore interconnectivity in the concrete. Extra care should be taken on $4 \%$ calcium nitrite mix since the AVPV is slightly higher than the general limit.

410 The AVPV and drying shrinkage results suggest that the addition of calcium nitrite affects the 411 cement paste microstructure - possibly increasing the number or size of pores in the cement paste (Figure S2). The pore structures have been reported to affect the compressive strength,

413 where a lower compressive strength is observed in concrete with a higher volume of pore 
414 structures [22]. However, the compressive strength in this study was not affected by the nitrite 415 admixture (section 3.3).

$416 \quad 3.5$ Leaching of nitrite from admixed concrete

417 The cumulative fraction of leached (CFL) nitrite from concrete cylinders with nitrite is reported 418 to be proportional to the square root of leaching time [25]. Therefore, the CFL of the concrete 419 with $1 \%, 2 \%$ and $3 \%$ calcium nitrite were calculated as functions of $\mathrm{t}^{0.5}$ in Figure 5. Except for 420 an initial transient region, an approximately linear correlation between the CFL and $\mathrm{t}^{0.5}$ is 421 evident for each specimen, which indicates that the leaching of nitrite is dominated by diffusion

422 [53]. The relative slower leaching rate during the initial transient period is commonly observed 423 in cylinders with casting surfaces $[25,54]$. This is attributed to the relatively lower nitrite 424 concentration near the concrete surface than the bulk concrete, which was caused by nitrite loss 425 during the curing.

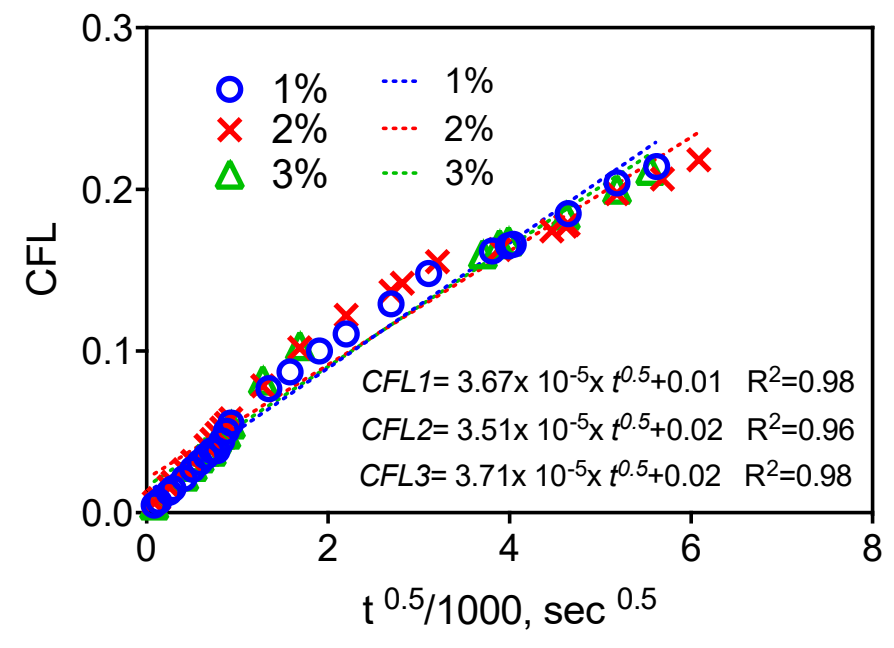

Figure 5 Cumulative fraction leached (CFL) of concrete with $1 \%, 2 \%$ and $3 \%$ calcium nitrite as an admixture.

429 The slopes of CFL versus $\mathrm{t}^{0.5}$ for all three dosages are similar, suggesting that the dosage level 430 doesn't affect the leaching performance in terms of CFL. The slopes ranged from $3.51 \times 10^{-5}$ $431 \mathrm{sec}^{-0.5}$ to $3.71 \times 10^{-5} \mathrm{sec}^{-0.5}$ for all three mixes, which is at the same magnitude determined in 
432 previous reports using concrete cylinders [25]. The similar slope observed for all these three 433 mixes suggests that in receiving water, the concentration of nitrite leached is linearly 434 proportional to the nitrite dosage in concrete. Therefore, a higher dosage of calcium nitrite in 435 concrete can induce a higher nitrite concentration in receiving water system, which may affect 436 the biofilm development in wastewater infrastructures.

The microbial communities were determined for biofilms developed on control coupons $(0 \%)$, and $2 \%$, and $4 \%$ calcium nitrite admixed coupons after being incubated in wastewater for 3 months (N0M3, N2M3, N4M3) and 6 months (N0M6, N2M6, N4M6). The microbial development on control coupons represents the normal concrete condition in the sewer 442 environment. Shannon index is widely used as an indicator for the alpha diversity of samples, 443 to describe the richness and evenness of microbial data [55]. The Shannon index observed for 444 all the coupons was $4.80-5.35$, which is similar to that previously observed in sewer biofilms 445 [56]. As shown in Figure 6, Desulfovibrio, Blvii28 wastewater-sludge group, Methanospirillum, Paludibacter, Smithella, Caldisericum, vadinBC27 wastewater-sludge

447 group, and Methanosaeta were found to be the top eight genera of microbes in the aspect of 448 abundance. All these microbes are commonly detected in anaerobic wastewater [26, 57-59]. 449 Desulfovibrio is a typical sulfate-reducing bacteria (SRB) that produces sulfide in the anaerobic parts of sewer facilities [26]. The phylum Latescibacteria is detected in the intestinal tracts of insects and is potentially relevant for organic removal in wastewater treatment [59].

452 Paludibacter and Caldisericum are found in wastewater-related reactors and have the ability 453 of reducing sulfur compounds to sulfide in wastewater [57, 60]. Methanosaeta and 454 Methanospirillum are methanogens, which are likely facilitating methane production [58].

455 Bacteria of the genus Smithella are propionate-oxidizing anaerobes that rely on syntrophic association with methanogens [58]. 


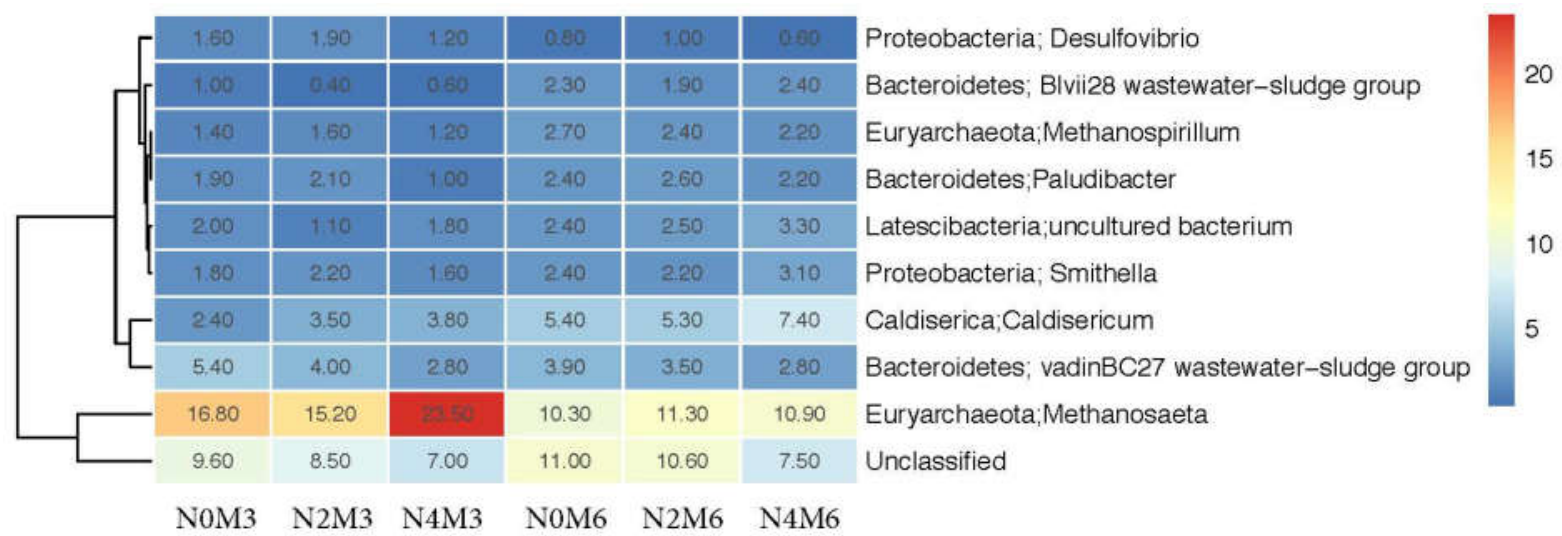

457

458 Figure 6 Heatmap summarizing the relative abundances of bacteria (each row representing an OTU) in

459 the biofilms collected from the surface of control coupons $(0 \%)$, and on $2 \%$, and $4 \%$ calcium nitrite

460 admixed coupons after being incubated in wastewater for 3 months (N0M3, N2M3, N4M3) and 6

461 months (N0M6, N2M6, N4M6). The relative abundance is defined as a percentage in total effective

462 microbial sequences in a sample. Reads that could not be classified are collectively referred to as

463 'unclassified'.

464

465 From the $3^{\text {rd }}$ month to $6^{\text {th }}$ month, the Shannon index of each coupon decreased slightly, from 4665.35 to 5.02 , from 5.30 to 5.16 and from 5.33 to 4.80 for the control, $2 \%$, and $4 \%$ calcium

467 nitrite coupons, respectively. The relative abundance increased for most of the microbes 468 including Blvii28 wastewater-sludge group, Methanospirillum, Paludibacter, Smithella,

469 Caldisericum and the phylum Latescibacteria after 6-month incubation. This observation is

470 consistent with the reduction of the Shannon index, suggesting the reduced diversity of biofilms

471 and the stabilization of abundant microbes [56]. After the same incubation time (3 months or

4726 months), the Shannon index of nitrite coupons were lower than the control coupons. This

473 implies that nitrite in concrete is a selective factor influencing the microbes that grow on the

474 surface of admixed concrete. 
475 After the first three months, the relative abundances of Caldisericum on nitrite coupons were $47645.8 \%$ and $58.3 \%$ higher for N2M3 and N4M3, respectively, compared with control coupons.

477 Similarly, after 6 months of incubation, the relative abundance of Caldisericum was still 19.2\%

478 higher on N4M6 than the control. The genus Caldisericum contains only a sole cultured species,

479 Caldisericum exile, isolated from a hot spring. The isolate is characterized as sulfur-reducing 480 bacteria (SRB), which can reduce thiosulfate and elemental sulfur but not sulfate [61]. Some 481 SRB are reported to have a nitrite reductase as a detoxification mechanism to survive in 482 environments containing nitrite [62]. However, the gene for this nitrite reductase was not 483 evident on the genome of Caldisericum exile. The reason for the increased relative abundance 484 of this SRB in the presence of nitrite is not evident. However, in a previous study, nitrite is 485 seen to stimulate biological sulfide oxidation within a sewer biofilm under anaerobic conditions 486 [63]. This causes increases in the formation of the intermediate sulfur compounds elemental 487 sulfur and thiosulfate, through the partial oxidation of sulfide [63]. Thus, a possibility here is 488 that the increased abundance of Caldisericum, in the presence of released nitrite, is related to 489 the increased availability of these intermediate sulfur-based substrates.

490 The relative abundance of Methanosaeta on N4M3 was 40.5\% higher than the control biofilm.

491 In some recent studies, Methanosaeta is found as the dominant methanogen in anaerobic 492 reactors with nitrite, where methanogenesis and denitrification were simultaneously occurring 493 [64]. This suggesting that Methanosaeta has some tolerance to nitrite, leading to its increased 494 abundance in N4M3. However, after the longer incubation, the impact of nitrite on the 495 abundance of Methanosaeta became insignificant (N4M6).

496 No significant difference was detected between control coupons and nitrite coupons for the 497 relative abundance of Desulfovibrio, Methanospirillum, Paludibacter, Latescibacteria and 498 Smithella after the 3 and 6 month incubations. In previous studies, the biocidal/inhibitory effect 
499 of nitrite for SRB and methanogens has been observed in sewer biofilms due to the formation

500 of free nitrous acid (FNA), the protonated form of nitrite [65, 66]. For SRB and methanogens,

501 at parts per billion (ppb) level, FNA inhibits the microbial metabolism and becomes a strong

502 biocidal agent, at parts per million ppm levels $[65,66]$. Based on the leaching performance of

503 nitrite (section 3.6), the maximum concentration of FNA in wastewater $(\mathrm{pH}=7)$ is excepted to

504 be around $0.24 \mathrm{ppb}$ and $0.48 \mathrm{ppb}$ for $2 \%$ and $4 \%$ coupons respectively. The microbial

505 community analysis of coupon biofilms suggests that these levels of FNA had no inhibitory effect on the SRB and methanogens. In contrast, the presence of Caldisericum was temporarily stimulated in the nitrite admixed concrete, possibly due to the formation of thiosulfate and elemental sulfur through nitrite oxidation of sulfide [67]. Overall, the influence of the nitrite admixture in concrete on the long-term development of sewer biofilms was negligible.

3. Conclusion:

511 This study investigated the feasibility of adding calcium nitrite as an admixture into sulfate 512 resistant cement for wastewater structures. Based on the results, the following conclusions are 513 drawn:

- The addition of calcium nitrite increased the setting time of paste, the slump, the drying shrinkage, and the AVPV of sulfate-resistant concrete. The addition reduced the water demand of the paste to achieve normal consistency. The properties of paste and concrete change with calcium nitrite dosages were linear relationships. A nitrite dosage of less than $4 \%$ is recommended to minimize the negative impacts on concrete mechanical properties.

- The compressive strength, the plastic density and the hardened density of concrete were not affected by calcium nitrite addition and they meet the requirement to be used for wastewater structures. 
- The cumulative fraction of leached nitrite is dominated by diffusion, which can be described as a linear function of $\mathrm{t}^{0.5}$. The CFL is independent of the dosage of calcium nitrite.

- The microbial community on admixed concrete surfaces reached comparable states to non-admixed concrete after 6 months, although some SRB such as Caldisericum was temporarily stimulated by nitrite from admixed concrete in sewage cultivation.

\section{Acknowledgements:}

The authors acknowledge the financial support provided by the Australian Research Council and the following partners: Gold Coast Water and Waste, District of Columbia Water and Sewer Authority, South East Water for their support through the Australian Research Council Linkage Project LP150101337. Dr. Guangming Jiang is the recipient of an Australian Research Council DECRA Fellowship (DE170100694). Xuan Li acknowledges the Chinese Scholarship Council for providing the Living Allowance Scholarship.

\section{Data availability}

The raw/processed data required to reproduce these findings cannot be shared at this time as the data also forms part of an ongoing study.

\section{References:}

[1] T.A. Söylev, M. Richardson, Corrosion inhibitors for steel in concrete: State of the art report, Construction and Building Materials, 22 (2008) 609-622.

[2] J. Sulikowski, J. Kozubal, The durability of a concrete sewer pipeline under deterioration by sulphate and chloride corrosion, Procedia Engineering, 153 (2016) 698-705.

[3] G. Jiang, J. Sun, K.R. Sharma, Z. Yuan, Corrosion and odor management in sewer systems, Current Opinion in Biotechnology, 33 (2015) 192-197. 
548 model of biodeterioration, chloride ingress and cracking for reinforced concrete structures,

549 Structural Safety, 30 (2008) 110-129.

550 [5] N. Delatte, Failure, distress and repair of concrete structures, Elsevier2009.

551 [6] G. Jiang, M. Zhou, T.H. Chiu, X. Sun, J. Keller, P.L. Bond, Wastewater-enhanced microbial

552 corrosion of concrete sewers, Environmental Science \& Technology, 50 (2016) 8084-8092.

553 [7] X. Li, G. Jiang, U. Kappler, P. Bond, The ecology of acidophilic microorganisms in the

554 corroding concrete sewer environment, Frontiers in Microbiology, 8 (2017) 683.

555 [8] R.L. Morton, W.A. Yanko, D.W. Graham, R.G. Arnold, Relationships between metal 556 concentrations and crown corrosion in Los Angeles County sewers, Research Journal of the

557 Water Pollution Control Federation, (1991) 789-798.

558 [9] G. Jiang, E. Wightman, B.C. Donose, Z. Yuan, P.L. Bond, J. Keller, The role of iron in 559 sulfide induced corrosion of sewer concrete, Water Research, 49 (2014) 166-174.

560 [10] P. Schieß1, M. Raupach, Laboratory studies and calculations on the influence of crack

561 width on chloride-induced corrosion of steel in concrete, Materials Journal, 94 (1997) 56-61.

562 [11] Y. Song, E. Wightman, Y. Tian, K. Jack, X. Li, H. Zhong, P.L. Bond, Z. Yuan, G. Jiang, 563 Corrosion of reinforcing steel in concrete sewers, Science of The Total Environment, (2018).

564 [12] A. ACI, 211.1-Standard Practice for Selecting Proportions for Normal, Heavyweight, and 565 Mass Concrete, 2002 (1991).

566 [13] AS3735-2001, Concrete structures for retainning liquids, in: T.A.W. Directory (Ed.), 567 Australian Water Association Publications, St. Leonards, Australia, 2011.

568 [14] P. Chindaprasirt, P. Kanchanda, A. Sathonsaowaphak, H.T. Cao, Sulfate resistance of 569 blended cements containing fly ash and rice husk ash, Construction and Building Materials, 21 $570 \quad$ (2007) 1356-1361. 
571 [15] C. Shi, J. Stegemann, Acid corrosion resistance of different cementing materials, Cement 572 and Concrete Research, 30 (2000) 803-808.

573 [16] R. François, S. Laurens, F. Deby, 1 - Steel Corrosion in Reinforced Concrete, in: R.

574 François, S. Laurens, F. Deby (Eds.) Corrosion and its Consequences for Reinforced Concrete 575 Structures, Elsevier2018, pp. 1-41.

576 [17] R. Leung, D. Li, W. Yu, H.K. Chui, T. Lee, M. Van Loosdrecht, G. Chen, Integration of 577 seawater and grey water reuse to maximize alternative water resource for coastal areas: the 578 case of the Hong Kong International Airport, Water Science and Technology, 65 (2012) 410579417.

580 [18] U.M. Angst, B. Elsener, C.K. Larsen, Ø. Vennesland, Chloride induced reinforcement 581 corrosion: electrochemical monitoring of initiation stage and chloride threshold values, 582 Corrosion Science, 53 (2011) 1451-1464.

583 [19] V. Ngala, C. Page, M. Page, Corrosion inhibitor systems for remedial treatment of 584 reinforced concrete. Part 1: calcium nitrite, Corrosion Science, 44 (2002) 2073-2087.

585 [20] Z. Li, B. Ma, J. Peng, M. Qi, The microstructure and sulfate resistance mechanism of high586 performance concrete containing CNI, Cement and Concrete Composites, 22 (2000) 369-377.

587 [21] N.S. Berke, A. Rosenberg, Technical review of calcium nitrite corrosion inhibitor in 588 concrete, Transportation Research Record, (1989).

589 [22] A.A. Malikyar, Y. Sudoh, N. Nakajima, S. Date, Influence of calcium nitrite based 590 accelerator, steam temperature and pre-curing time on the compressive strength of 591 Mortar/Concrete, International Journal of Engineering and Technology, 10 (2018).

592 [23] G. De Schutter, L. Luo, Effect of corrosion inhibiting admixtures on concrete properties, 593 Construction and Building Materials, 18 (2004) 483-489. 
594 [24] M. Inoue, H. Choi, Y. Sudoh, K. Ayuta, Experimental study of leaching and penetration 595 of nitrite ions in nitrite-type repair materials on the surface of concrete, Advances in 596 Technology Innovation, 2 (2017) 22-24.

597 [25] H. Liang, L. Li, N. Poor, A. Sagüés, Nitrite diffusivity in calcium nitrite-admixed hardened 598 concrete, Cement and Concrete Research, 33 (2003) 139-146.

599 [26] H. Satoh, M. Odagiri, T. Ito, S. Okabe, Microbial community structures and in situ sulfate600 reducing and sulfur-oxidizing activities in biofilms developed on mortar specimens in a 601 corroded sewer system, Water research, 43 (2009) 4729-4739.

602 [27] G. Jiang, O. Gutierrez, K.R. Sharma, Z. Yuan, Effects of nitrite concentration and 603 exposure time on sulfide and methane production in sewer systems, Water Research, 44 (2010) $604 \quad 4241-4251$.

605 [28] AS2972, General Purpose and Blended Cements, Standards, Australia, 2010.

606 [29] AS1012.2, Methods of Testing Concrete; Method 2: Preparation of the Concrete Mixes in 607 the Laboratory, Standards Australia, Sydney, 2014.

608 [30] AS/NZS2350.4, Methods of testing portland, blended and masonry cement, Method 4: 609 Setting time, Standards Australian/Standards New Zealand, 2006.

610 [31] AS1012.3.1, Methods of Testing Concrete, Method 3.1: Determination of properties 611 related to the consistency of concrete - Slump test., Standards Australian, Sydney, 2014.

612 [32] AS1012.9, Methods of testing concrete-Compressive strength tests-Concrete, mortar and 613 grout specimens, SAI Global, Sydney, Standards Australian, 2014.

614 [33] AS1012.8.4, Methods of Testing Concrete, Method 8.4: Method of making and curing 615 concrete - Drying shrinkage specimens prepared in the field or in the laboratory, Standards 616 Australia, Sydney, 2015. 
617 [34] AS1012.13, Methods of Testing Concrete; Method 13: Determination of the Drying

618 Shrinkage of the Concrete Samples Prepared in the Field or in the Laboratory, Standards

619 Australia, 2015.

620 [35] AS1012.21, Methods of testing concrete, Method 21: Determination of water absorption 621 and apparent permeable voids in hardened concrete, Standards Australian, Sydney, 1999.

622 [36] ANSI/ANS-16.1, Measurement of the leachability of solidified low-level radioactive 623 wastes by a short-term test procedure, American Nuclear Society, 1986.

624 [37] X. Li, F. Khademi, Y. Liu, M. Akbari, C. Wang, P.L. Bond, J. Keller, G. Jiang, Evaluation 625 of data-driven models for predicting the service life of concrete sewer pipes subjected to 626 corrosion, Journal of Environmental Management, 234 (2019) 431-439.

627 [38] A.U. Elinwa, Y.A. Mahmood, Ash from timber waste as cement replacement material, 628 Cement and Concrete Composites, 24 (2002) 219-222.

629 [39] L. Turanli, B. Uzal, F. Bektas, Effect of material characteristics on the properties of 630 blended cements containing high volumes of natural pozzolans, Cement and Concrete Research, 63134 (2004) 2277-2282.

632 [40] J. Murata, Flow and deformation of fresh concrete, Matériaux et Construction, 17 (1984) $633 \quad 117-129$.

634 [41] K. Vijai, R. Kumutha, B. Vishnuram, Effect of types of curing on strength of geopolymer 635 concrete, International Journal of Physical Sciences, 5 (2010) 1419-1423.

636 [42] I. Kondratova, P. Montes, T. Bremner, Natural marine exposure results for reinforced 637 concrete slabs with corrosion inhibitors, Cement and Concrete Composites, 25 (2003) 483-490. 638 [43] M.C. Brown, R.E. Weyers, M.M. Sprinkel, Effect of corrosion-inhibiting admixtures on 639 material properties of concrete, Materials Journal, 98 (2001) 240-250.

640 [44] A.M. Neville, J.J. Brooks, Concrete technology, Longman Scientific \& Technical 641 England1987. 
642 [45] W. Zhang, M. Zakaria, Y. Hama, Influence of aggregate materials characteristics on the 643 drying shrinkage properties of mortar and concrete, Construction and Building Materials, 49 644 (2013) 500-510.

645 [46] J. Bae, N. Berke, R. Hoopes, J. Malone, Freezing and thawing resistance of concretes with 646 shrinkage reducing admixtures, International RILEM Workshop on Frost Resistance of 647 Concrete, RILEM Publications SARL, 2002, pp. 327-333.

648 [47] Z. Li, M. Qi, Z. Li, B. Ma, Crack width of high-performance concrete due to restrained 649 shrinkage, Journal of Materials in Civil Engineering, 11 (1999) 214-223.

650 [48] A. Gonzalez-Corominas, M. Etxeberria, Effects of using recycled concrete aggregates on 651 the shrinkage of high performance concrete, Construction and Building Materials, 115 (2016) $652 \quad 32-41$.

653

[49] M. Olivia, P. Sarker, H. Nikraz, Water penetrability of low calcium fly ash geopolymer 654 concrete, Proc. ICCBT2008-A, 46 (2008) 517-530.

655 [50] K. Pasupathy, M. Berndt, J. Sanjayan, P. Rajeev, D.S. Cheema, Durability Performance 656 of Precast Fly Ash-Based Geopolymer Concrete under Atmospheric Exposure Conditions, 657 Journal of Materials in Civil Engineering, 30 (2018) 04018007.

658 [51] M. Albitar, M.M. Ali, P. Visintin, M. Drechsler, Durability evaluation of geopolymer and 659 conventional concretes, Construction and Building Materials, 136 (2017) 374-385.

660 [52] F. VicRoads, Standard Specifications for Road works and Bridge works, VicRoads 661 Melbourne, 2006.

662 [53] J. Tritthart, P. Banfill, Nitrite binding in cement, Cement and concrete research, 31 (2001) $663 \quad 1093-1100$.

664 [54] E. Rozière, A. Loukili, R. El Hachem, F. Grondin, Durability of concrete exposed to 665 leaching and external sulphate attacks, Cement and Concrete Research, 39 (2009) 1188-1198. 
667 J.K. Harris, On the use of diversity measures in longitudinal sequencing studies of microbial communities, Frontiers in microbiology, 9 (2018) 1037.

669 [56] P. Jin, X. Shi, G. Sun, L. Yang, Y. Cai, X.C. Wang, Co-variation between distribution of 670 microbial communities and biological metabolization of organics in urban sewer systems, 671 Environmental Science \& Technology, 52 (2018) 1270-1279.

672 [57] Y. Zhang, X. Wang, M. Hu, P. Li, Effect of hydraulic retention time (HRT) on the 673 biodegradation of trichloroethylene wastewater and anaerobic bacterial community in the 674 UASB reactor, Applied Microbiology and Biotechnology, 99 (2015) 1977-1987.

675 [58] M. Sobrieraj, D. Boone, Smithella Liu, Balkwill, Aldrich, Drake and Boone 1999, 553 VP, 676 Bergey’s Manual ${ }^{\circledR}$ of Systematic Bacteriology, (2005) 1039-1040.

677 [59] C. Walden, F. Carbonero, W. Zhang, Assessing impacts of DNA extraction methods on 678 next generation sequencing of water and wastewater samples, Journal of Microbiological 679 Methods, 141 (2017) 10-16.

680 [60] F. Liang, Y. Xiao, F. Zhao, Effect of $\mathrm{pH}$ on sulfate removal from wastewater using a 681 bioelectrochemical system, Chemical Engineering Journal, 218 (2013) 147-153.

682 [61] K. Mori, K. Yamaguchi, Y. Sakiyama, T. Urabe, K.-i. Suzuki, Caldisericum exile gen. 683 nov., sp. nov., an anaerobic, thermophilic, filamentous bacterium of a novel bacterial phylum,

684 Caldiserica phyl. nov., originally called the candidate phylum OP5, and description of 685 Caldisericaceae fam. nov., Caldisericales ord. nov. and Caldisericia classis nov, International 686 Journal of Systematic and Evolutionary Microbiology, 59 (2009) 2894-2898.

687 [62] S.-H. Gao, J.Y. Ho, L. Fan, D.J. Richardson, Z. Yuan, P.L. Bond, Antimicrobial effects 688 of free nitrous acid on Desulfovibrio vulgaris: implications for sulfide-induced corrosion of concrete, Applied Environmental Microbiology, 82 (2016) 5563-5575. 
690 [63] J. Mohanakrishnan, O. Gutierrez, R.L. Meyer, Z. Yuan, Nitrite effectively inhibits sulfide

691 and methane production in a laboratory scale sewer reactor, Water research, 42 (2008) 3961-

6923971.

693 [64] T. Allegue, A. Arias, N. Fernandez-Gonzalez, F. Omil, J. Garrido, Enrichment of nitrite694 dependent anaerobic methane oxidizing bacteria in a membrane bioreactor, Chemical 695 Engineering Journal, 347 (2018) 721-730.

696 [65] G. Jiang, O. Gutierrez, Z. Yuan, The strong biocidal effect of free nitrous acid on anaerobic 697 sewer biofilms, Water research, 45 (2011) 3735-3743.

698 [66] G. Jiang, A. Keating, S. Corrie, K. O'halloran, L. Nguyen, Z. Yuan, Dosing free nitrous 699 acid for sulfide control in sewers: results of field trials in Australia, Water research, 47 (2013) $700 \quad 4331-4339$.

701 [67] G. Jiang, K.R. Sharma, A. Guisasola, J. Keller, Z. Yuan, Sulfur transformation in rising 702 main sewers receiving nitrate dosage, Water research, 43 (2009) 4430-4440. 